\title{
Uma Bibliografia do Violão Brasileiro (1916-1990)
}

\author{
Paulo Castagna e Werner Schwarz
}

\section{Introdução}

O violão, a partir da década de 1920 , destacou-se, em todo o mundo, como instrumento de grande penetração social e amplos recursos musicais, recebendo a atenção da maioria dos compositores que atuaram a partir dessa época.

A enorme produção musical para o instrumento e a redescoberta do repertório violonístico anterior ao século $\mathrm{XX}$, motivaram a publicação de livros, artigos, teses, catálogos, bibliografias, discografias e dicionários, com a finalidade de organizar todo esse material, subsidiar as histórias da música para violão e permitir rápido acesso às informações, gravações e partituras desejadas.

A música brasileira para o instrumento, que teve uma rápida evolução em nosso século e uma aceitação internacional sem precedentes, não recebeu a mesma sistematização, estando, ainda, pouco representada em trabalhos dessa natureza.

Este artigo é a primeira tentativa de reunir as publicações feitas entre 1916 e 1990, sobre a música "erudita" e "popular" para violão e instrumentos similares (viola, cavaquinho, guitarra, etc.), violonistas, professores e construtores brasileiros, sem as quais seria impossível iniciar estudos de maiores proporções sobre o assunto. 1916 é, ao mesmo tempo, a data dos textos mais antigos que encontramos e o ano em que o violão começa a ser aceito, no país, como instrumento solista e de concerto.

As 490 referências bibliográficas que apresentamos foram colecionadas durante 5 anos e encontradas em bibliografias (citadas no ítem III) e/ou nos acervos pesquisados. 
No Brasil, o trabalho foi desenvolvido na Biblioteca Nacional (Rio de Janeiro), na Biblioteca Municipal Mário de Andrade (São Paulo), na Biblioteca e Fonoteca da Escola de Comunicações e Artes da USP, na Biblioteca do Instituto de Estudos Brasileiros da USP, na Biblioteca e Discoteca do Centro Cultural São Paulo, no Arquivo do Estado de São Paulo e em bibliotecas particulares. Na Alemanha a pesquisa foi realizada na Bayerischen Staatsbibliothek de Munique e na Universitätsbibliothek de Augsburg.

Nossa bibliografia ainda não é completa, uma vez que não foi possível a consulta sistemática de jornais e revistas não repertoriadas nas bibliografias da música brasileira. Incluímos artigos desse tipo de periódico somente quando encontrados em hemerotecas ou em acervos particulares, muitos deles, infelizmente, sem a referência bibliográfica correta.

Os autores agradecerão a toda e qualquer colaboração dos leitores, no sentido de enviareminformações que possam completar, corrigir ou acrescentar quaisquer citações bibliográficas deste trabalho.

\section{Seções da bibliografia}

1. Revistas nacionais especializadas. Repertoriamos, neste ítem, todas as revistas brasileiras de música para violão encontradas. A maioria delas, no entanto, está voltada à publicação de músicas cifradas para canto $\mathrm{e}$ violão. Somente as revistas O Violão(1928-1929), A Voz do Violão (1931) e Violão e Mestres (1964-1968) são especializadas em artigos sobre a música para o instrumento.

2. Artigos, livrose teses. Incluímos, aqui, somente os trabalhos que destinem a maior parte de seu espaço a assuntos ligados ao violão brasileiro. Por medida de economia, deixamos de publicar um índice onomástico ou de assunto, mas completamos algumas referências com informações, entre colchetes e em itálico, que facilitem a identificação do tema tratado.

3. Obras de referência. Nesta seçãa estão indicadas as bibliografias, discografias, catálogos, enciclopédias e dicionários com informações sobre o violão e instrumentos similares no Brasil. Não publicamos a relação detalhada dos verbetes e entradas que tratam da matéria, mas 
advertimos que as fontes mais ricas em informações sobre o assunto são - Dicionario de guitarristas, de Domingo Prat e a Enciclopédia da música brasileira. Sobre os instrumentos folclóricos, as fontes mais indicadas são - Dicionário do folclore brasileiro, de Luís da Câmara Cascudo e o Dicionário musical brasileiro, de Mário de Andrade. Três bibliografias foram fundamentais para este trabalho: a Bibliografia de música brasileira (1977), organizada por Antonio Barone e Luís Milanesi, ainda inédita, a Guitar bibliography (1984), de Werner Schwarz, com a colaboração de Monika Maringer e a Bibliografia da música brasileira 1977-1984 (1988), organizada por Irati Antonio, Rita Rodrigues e Heloísa Bauab. Com relação aos catálogos, relacionamos somente aqueles que se referem a editoras ou a violonistas. Deixamos de incluir catálogos de compositores não violonistas, como aqueles publicados entre 1975 e 1980, pelo Depto. de Cooperação Cultural, Científica e Tecnológica do Ministério das Relações Exteriores e os catálogos preparados entre 1977 e 1981 pela Biblioteca da Escola de Comunicações e Artes da USP, bastante conhecidos e já enumerados nas Bibliografias de 1977 e 1988.

\section{I - Revistas Nacionais Especializadas em Música para Violão}

1. Coleção internacional: violão e guitarra. São Paulo, publicação mensal da IMPRIMA Comunicação, 1979.

2. A grande parada: violão e guitarra. São Paulo, publicação bimestral da IMPRIMA Comunicação, 1981.

3. Internacional: violão e guitarra. São Paulo, publicação da IMPRIMA Comunicação e Editoração Ltda., 1978-1986.

4. Método violão e guitarra: teoria e repertório. São Paulo, publicação mensal da IMPRIMA Comunicação, 1981.

5. MPB: violão e guitarra. São Paulo, editada pela IMPRIMA Comunicação Editorial Ltda., 1980-1986.

6. Seleção de músicas; músicas para violão e guitarra. São Paulo, IMPRIMA, 1982-1984.

7. Série ouro: suplemento da revista violão e guitarra. São Paulo, 1979.

8. Sucessos: violão e guitarra. São Paulo, publicação anual da IMPRIMA Comunicação, 1980-1984.

9. Súper violão e guitarra: músicas cifradas para violão e guitarra. São Paulo, publicação anual da IMPRIMA Comunicação, 1979-1983.

10. Vamos cantar? Rio de Janeiro, 1951-1966.

11. O Violão. Rio de Janeiro, direção de B. Dantas de Souza Pombo, 19271929. 
12. Violão \& guitarra: as melhores músicas do momento para você cantare tocar. São Paulo, publicação mensal da IMPRIMA, 1975-1986.

13. Violão e guitarra especial: os poetas. São Paulo, editado pela IMPRIMA Comunicação, 1979-1981.

14. Violão e Mestres; magazine. São Paulo, Violões Giannini S.A., 19641968.

15. Violão e viola sertaneja. São Paulo, publicação mensal da IMPRIMA Comunicação Editorial Ltda., 1980-1986.

16. Violão mágico: aprenda a tocar facilmente. São Paulo, publicação mensal da IMPRIMA Comunicação, 1980-1981.

17. Violão; solo \& acompanhamento; método moderno de violão em solo e acompanhamento. São Paulo, IMPRIMA, 1982-1984.

18. Viva cantando: músicas cifradas para violão e guitarra. São Paulo, publicação mensal das IMPRIMA Comunicação, 1931.

19. A Voz do Violão; revista mensal. Rio de Janeiro, 1931.

\section{II - ARTIGOS, LIVROS E TESES SOBRE O VIOLÃO E INSTRUMENTOS SIMILARES NO BRASIL}

20. ABLONIZ, Miguel. More about the Choro. Guitar News, Cheltenham, $\mathrm{n}^{\circ} 45$, p. 12 , nov./dez. 1958.

21. ABREU E SOUSA, Candido de. Uma opinião que deve ser conhecida [Manduca Jacome]. O Violão, Rio de Janeiro, ano 1, $\mathrm{n}^{\circ}$ 3, [p. 23-25], fev. .1929.

22. AGUIAR, Marcel di. Chico Danta da viola. Folclore, Vitória, n 93, p. 15, dez. 1980.

23. ALDAY, Jim. Del Vecchio's Resonator Guitar. Guitar player, Saratoga, v. $20, n^{\circ} 3$, p. $52-54,1986$.

24. [ALMEIDA, Ricardo Augusto Porto de]. Os amplificadores brasileiros. In: DENYER, Ralph. Toque; curso completo de violão \& guitarra. Rio de Janeiro, Rio Gráfica e Editora Ltda., 1982. p. 70-71.

25. [ALMEIDA, Ricardo Augusto Porto de]. Componentes nacionais. In: DENYER, Ralph. Toque. op. cit., p. 140-141.

26. [ALMEIDA, Ricardo Augusto Porto de]. Os contrabaixos brasileiros. In: DENYER, Ralph. Toque. op. cit., p. 148-149.

27. [ALMEIDA, Ricardo Augusto Porto de]. As guitarras brasileiras. In: DENYER, Ralph. Toque. op. cit., p. 92-95.

28. [ALMEIDA, Ricardo Augusto Porto de]. Os instrumentos brasileiros. In: DENYER, Ralph. Toque. op. cit., p. 26-31. 
29. ALMEIDA, Sergio Pinto de. Um violão tocado ao avesso [Américo Jacomino]. Folha de S. Paulo, Ilustrada, São Paulo, ano 57, $\mathrm{n}^{\circ}$ 18.165, p. 35, quarta-feira, 27 dez. 1978.

30. Americo Jacomino. O Estado de S. Paulo, São Paulo, ano 42, no 13.769, p. 5, col. Artes e Artistas, terça-feira, 5 set. 1916.

31. Americo Jacomino-O trespasse do conhecido violonista brasileiro. Folha da Noite, São Paulo, ano 8, nº 2.392, p. 5, sábado, 8 set. 1928.

32. ANDRADE, Julieta. Cocho mato-grossense, um alaúde brasileiro. São Paulo, Escola de Folclore e Editorial Livramento, 1981, 85 p.

33. ANDRADE, Julieta. Pesquisa de folclore no Mato Grosso: siriri, cana verde, viola de cocho, cururu. Cultura, Brasília, v. 7, $\mathrm{n}^{\circ} 25$, p. 88-96, abr./ jun. 1977.

34. ANDRADE, Mário de. Renascimento do violão. Diário Nacional, São Paulo, ano $2, \mathrm{n}^{\circ} 603$, p. 7, quinta-feira, 20 jun. 1929.

35. Ângela [Muner]. Violão e Mestres, São Paulo, v. 2, no 8, p. 11-15, dez. 1985.

36. ÂNGELO, Assis. Quinteto violado. Folhetim, São Paulo, n ${ }^{\circ}$ 125, p.7, jun. 1979.

37. ÂNGELO, Assis. Violas e violões. Folhetim, São Paulo, $n^{\circ} 128$, p. 5-7, jul. 1979.

38. ANIDO, Maria Luiza. Villa-Lobos e o violão. In: BRASIL, Ministério da Educação e Cultura \& MUSEU VILLA-LOBOS. Presença de VillaLobos. Rio de Janeiro, Ministério da Educação e Cultura, 1969. v. 3, p. 123-145.

39. Antonio Rebello. Violão e Mestres, São Paulo, [v.1], n 4, p. 12-14, [63], set. 1965.

40. Antonio Simalha. Violão e Mestres, São Paulo, [v.1], nº 5, p. 26, jun. 1966.

41. ANTONIO, Irati \& PEREIRA, Regina. Garoto, sinal dos tempos. Rio de Janeiro, FUNARTE, 1982. 100p. (MPB, v. 5)

42. ANTONIO, Irati. A arte do violão brasileiro numa homenagem a Garoto. Folha de São Paulo, Ilustrada, São Paulo, ano 66, no 20.829, p. 93, domingo, 13 abr. 1986.

43. ANTONIO, Paulo. Sávio homenageado em Pôrto Alegre. Violão $e$ Mestres, v. 2, nº 9, p. 27-28, nov. 1968.

44. Apontamentos sobre o violão em Campinas. Violão e Mestres, São Paulo, [v.1], n 6, p. 4-8, set. 1966.

45. APPLEBY, Wilfrid M. The choro and Villa-Lobos. Guitar news, $\mathrm{n}^{\circ} 44$, p. 21, set.-out. 1958 .

46. Uma apresentação [Heddy Cajueiro]. O Violão, Rio de Janeiro, ano $1, \mathrm{n}^{\circ}$ 10, [p. 23], nov./dez. 1929.

47. ARAUJO, Raimundo. Cantador, verso e viola. Rio de Janeiro, Editora Pongetti, 1974. 
48. Armandinho, chorão paulista, coração brasileiro. Urubumalandro, São Paulo, número especial, p. 7-11, ago. 1978.

49. Um artista que é um grande autodidacta [Benedicto Chaves, "Gurú"]. Diário Nacional, São Paulo, ano 2, n 490, p. 7, 6 fev. 1928.

50. The Assad Brothers: interviewed by Bauke Oosterhout. Classical guitar, Gateshead, v. 4, nº 5, p. 11-15, 1986.

51. Os astros brasileiros do violão [José Augusto de Freitas]. A Voz do Violão, Rio de Janeiro, ano 1, n 3, p. 10-11, abr. 1931.

52. Os astros brasileiros do violão [Mozart Bicalho]. A Voz do Violão, Rio de Janeiro, ano 1, n 1, p. 11-12, fev. 1931.

53. Os astros brasileiros do violão [Rogério Guimarães]. A Voz do Violão, Rio de Janeiro, ano 1, n 2, p. 11-12, mar. 1931.

54. Uma audição de Rossini Silva. O Violão, Rio de Janeiro, ano 1, n 10, [p. 9-10], nov./dez. 1929.

55. AZEVEDO, Luis Heitor Corrêa de. La guitarre archaïque au Brésil. In: Studia memoriae Bela Bartok Sacra. Budapest, Akadémiai Kiadó, 1956. p. 123-124.

56. AZEVEDO, Luis Heitor Corrêa de. A "moda de viola" no Brasil central. Cultura Política, Rio de Janeiro, v. 3, n 32, p. 181-184, set. 1943.

57. AZEVEDO, Luis Heitor Corrêa de. Instrumentos de música do cantador nordestino. In: CENTRO DE PESQUISAS DA ESCOLA NACIONAL DE MUSICA. Relação dos discos gravados no estado do Ceará (janeiro a fevereiro de 1943). Rio de Janeiro, Escola Nacional de Música, 1953. p. 52-56.

58. AZEVEDO, Luis Heitor Corrêa de. Instrumentos de música do cantador nordestino. Cultura Política, Rio de Janeiro, v. 4, n 45 p. 149-153, out. 1944.

59. AZEVEDO, Luis Heitor Corrêa de. Violas de Goiaz. Cultura Política, Rio de Janeiro, v. 3, n 34, p. 293-296, nov. 1943.

60. AZEVEDO, Luis Heitor Corrêa de. Violas de Goiaz. In: CENTRO DE PESQUISASFOLCLÓRICAS DA ESCOLA NACIONAL DEMUSICA. Relação dos discos gravados no estado de Minas Gerais (fevereiro de 1944). Rio de Janeiro, Escola Nacional de Música, 1956. p. 34-38.

61. AZEVEDO, Luis Heitor Corrêa de. Violas deDiamantina. In: CENTRO DE PESQUISAS FOLCLÓRICAS DA ESCOLA NACIONAL DE MUSICA. Relação dos discos gravados no estado do Rio Grande do Sul (janeiro de 1946). Rio de Janeiro, Escola Nacional de Música, 1959. p.87-91.

62. AZEVEDO, Luiz Heitor Corrêa de. Oude gitaarsoorten in Brazilie. Kithara, Hilversum, ${ }^{\circ} 4$, p. 5, 1962.

63. B.P. Sobre a guitarra. Resenha Musical, São Paulo, v. 4, n 40, p.6, dez. 1941. 
64. BANDEIRA, Manuel. Literatura do violão. Ariel, São Paulo, v. $2, \mathrm{n}^{\circ} 13$, p. 463 , out. 1924.

65. BANDEIRA, Manuel. A literatura do violão. O Estado de S. Paulo, São Paulo, ano 61, $\mathrm{n}^{\circ} 20.179$, p.3, terça-feira, 30 jul. 1935.

66. Com Barbosa Lima [Antonio Carlos] em 65. Violão e mestres, São Paulo, [v.1], no 3, p. 4-11, mar. 1965

67. Barbosa Lima no Rio. Violão e Mestres, São Paulo, [v.1], nº 4, p. 60, set. 1965.

68. BARBOSA-LIMA, Carlos. "Sons de Carrilhões". Guitar International, v. $14, n^{\circ} 5$, p. 16-19, dez. 1985.

69. BARBOSA-LIMA, Carlos. Modinha and the Brazilian soul. Guitar International, v. 14, $\mathrm{n}^{\circ} 1$, p. 32-34, ago. 1985.

70. BARBOSA-LIMA, Carlos; BOBRI, Vladimir; NELSON, Martha. A musical journey to many lands: Brazil. Guitar review, New York, ${ }^{\circ} 47$, p. 16-17, 22, spring, 1980.

71. BARROSO, Gustavo. Ao som da viola. Rio de Janeiro, Leite Ribeiro, $1921.782 \mathrm{p}$.

72. BASTIAN, Dorothy. Marcelo Kayath at Merkin Hall Guitar Review, New York, $n^{\circ} 61$, p. 37, 1985.

73. Uma boa noticia para os estudiosos [João Pereira]. O Violão, Rio de Janeiro, ano 1, no 8, [p. 31], ago./set. 1929.

74. BOBRI, Vladimir. King of the Bossa Nova: spotlight on Antonio Carlos Jobim. Guitar Review, New York, n' 55, p. 1-7, 1983.

75. Bom signal. O Violão, Rio de Janeiro, ano 1, no 8, [p. 22], ago./set. 1929.

76. Bonfá, um homem e seu violão. Violão e Mestres, São Paulo, v. $2, n^{\circ} 8$, p. 16-19, dez. 1967.

77. BOSMAN, Lance. Carlos Barbosa-Lima: widening vistas. Guitar International, v. 18, nº 6, p. 24-27, 1989/1990.

78. Um brasileiro na Suíça [José Barrense Dias]. Violão e Mestres, São Paulo, v. $2, \mathrm{n}^{\circ} 9$, p. 26, nov. 1968.

79. The Brazilian Guitar; transcribed and edited by Brian Hodel. San Francisco, Dennis McMillan Paublishing, s.d., 75 p.

80. CALADO, Carlos A. Resenha: Garoto. Caderno de Música, São Paulo, $\mathrm{n}^{\circ} 13$, p. $16,1984$.

81. CAMILETTI. Simonetta. Heitor Villa-Lobos e la chitarra. Il Fronimo, Milano, v. $15, n^{\circ} 59$, p. 28-40; v. 15, $n^{\circ} 60$, p.7-18.

82. CAMILETTI, Simonetta. Le opere per chitarra di Heitor Villa-Lobos nel contesto musicale brasiliano: i dodici studi. Roma, UNIVERSITA DEGLI STUDI DI ROMA "LA SAPIENZA". FACOLTA DI LETTERE E FILOSOFIA. Tesi di Laurea, 1986. $224 \mathrm{f}$.

83. CAMPOS, Eduardo. Cantador, musa e viola. Rio de Janeiro, Americana, 
Brasilia, Instituto Nacional do Livro, 1973, 172 p.

84. Canhoto [Américo Jacomino]e Jundiaí, uma estreita ligação. Jornal de Jundiaí, Jundiai, 7 jan. 1979.

85. Carlos Barbosa-Lima. Guitar Review, New York, nº 55, p. 29, 1983.

86. Carlos Barbosa-Lima. Guitar, London, jul.1973.

87. Carlos Barbosa-Lima. Violão e Mestres, v. 1, n 3, p. 4-11, 1965.

88. O Carnaval que passou... A Voz do Violão, Rio de Janeiro, ano $1, \mathrm{n}^{\circ} 1, \mathrm{p}$. 9, fev. 1931.

89. Uma carta de Osmar Abreu sobre Sérgio e Eduardo [Abreu]. Violão e Mestres, São Paulo, v. 2, n 9, p. 29-30, nov. 1968.

90. A casa da arte. Violão e Mestres, São Paulo, v. 2, n 9, p. 17-20, nov. 1968.

91. CASCUDO, Luis da Câmara. O cavaquinho é brasileiro. Fronteiras, Recife, v. 8, n 11, p. 1-2, nov. 1939.

92. CHEDIAK, Almir. Dicionário de acordes cifrados: harmonia aplicada à música popular. São Paulo, Irmãos Vitale, 1984. 357 p.

93. The chôro and Villa-Lobos. Guitar News, Cheltenham, n 44, p. 21, 1958.

94. "Circulo Violonístico Villa-Lobos". Violão e Mestres, v. 2, n 9, p. 4041, nov. 1968.

95. CIURLO, E. Fausto. Chitarra carioca [Américo Jacomino]. Chitarrae Musica, Ancona, ago. 1967.

96. CLA VER FILHO, José. Smetak capta o som do violão ao vento. Correio Brasiliense, Brasília, 14 set. 1975.

97. CLINTON, George. Guitar advises: Villa-Lobos Study $n^{\circ}$ 1. Guitar International, v. 15, n 3, p. 49, 1986/1987.

98. CLINTON, George. Guitar Fiesta: Wigmore Hall, 18th october 1987; concert to honour Heitor Villa-Lobos. Guitar International, v. 16, n ${ }^{\circ} 5$, p. 26-27, 1987/1988.

99. CLINTON, George. A pleasant interlude: Marcelo Kayath. Guitar International, v. 18, n. 12, p. 6-7, 1989/1990.

100. CLINTON, George. Sérgio Abreu. Guitar, London, n 7, p. 22-24, jan. 1979.

101. CLINTON, George. Turibio Santos. Guitar, London, v. 2, n 11, p. 2022, 1974.

102. CLOSE, Denis. "Sete cordas": the Brazilian guitar. GuitarInternational, v. $14, \mathrm{n}^{\circ} 1$, p. 11-13, ago. 1985.

103. COELHO, Olga [Praguer]. The guitar in Brazil... and some reminiscences. Guitar Review, New York, n² 21, p. 16-18, 1957.

104. [COELHO], Olga Pragner. O que é nosso. O Violão, Rio de Janeiro, ano 1, no 7, [p. 11-12[, jul. 1929.

105. Como nossos intellectuaes apreciam o violão [Gastão Penalva]. A Voz do Violão, Rio de Janeiro, ano 1, n 3, p. 13-14, abr. 1931. 
106. Un concierto de dos excelentes guitarristas. Violão e Mestres, São Paulo, [v.1], no 5, p. 52-53, jun. 1966.

107. A conversation with a Chorão: Nicanor Teixeira. Guitar Review, New York, $\mathrm{n}^{\circ} 73$, p. 34-35, 1988.

108. COOPER, Colin. Marcelo Kayath on the way to the top. Classical Guitar, Gateshead, v. 4, no 10, p. 11-16, 1986.

109. CORREA, Roberto Nunes. Viola caipira, Brasilia, Musimed, 1983. 103 $\mathrm{p}$.

110. COSTA, Duarte. A feliz criação no Brasil da revista "Violão e Mestres". Violão e Mestres, São Paulo, [v.1], nº 3, p. 42, mar. 1965.

111. Creou-se no Rio, o Centro Artistico Regional. O Violão, Rio de Janeiro, ano 1, n ${ }^{\circ}$ 2, [p. 32-33], jan. 1929.

112. Os criticos... [Oscar Guanabarino e Imbassaby]. O Violão, ano 1, $\mathrm{n}^{\circ} 10$, [p. 8], nov./dez. 1929.

113. A cultura do Violão em S. Paulo. O Violão, Rio de Janeiro, ano $1, \mathrm{n}^{\circ} 1$, [p. 19], dez. 1928.

114. Curso de violão na Academia Lorenzo Fernandez. Violão e Mestres, São Paulo, [v.1], nº 4, p. 32-33, set. 1965.

115. DANNER, Peter. Obituary: Radamés Gnatalli. The Soundboard, Cypress, v. $15, n^{\circ} 1$, p. $19,1988$.

116. Darcy Villa-Verde. Violão e Mestres, São Paulo, v. 1, n. 4, p. 34-35, set. 1965.

117. Dentro em breve o "Correio da Manhâ" promoverá o grande concurso. $O$ Violão, Rio de Janeiro, ano 1, n 7, [p. 15], jul. 1929.

118. DENYER, Ralph. Toque; curso de violão \& guitarra. Rio de Janeiro, Rio Gráfica e Editora Ltda., 1982-1983. 327p.

119. DEXTER, Will. Turíbio Santos. Guitar News, Cheltenham, no 97, p. 11$12,1968$.

120. DIAS, José Américo. O Hendrix da V. Madalena [Itamar Assunção]. Canja, São Paulo, v. 1, nº 15, p. 16, out. 1980.

121. Die Zukunft der Gitarre in Brasilien. Peter Päffgen im Gespräch mit Martin Müller. Gitarre und Laute, Kassel, v. 11, n 5, p. 9-14, 1989.

122. Dilermando Reis. Violão e Mestres, São Paulo, v. 1, n. 4, p. 14-15, set. 1965.

123. Dilermando: "Violão não é instrumento ingrato", Violão e Mestres, São Paulo, [v.1], no 4, p. 15-19, set. 1965.

124. Dois astros na canção regional [Stefana de Macedo e Gesy Barbosa]. O Violão, Rio de Janeiro, ano 1, no 1, [p. 18], dez. 1928.

125. DUARTE, John W. Carlos Barbosa-Lima. B.M.G., London, v. 69, $\mathrm{n}^{\circ} 806$, p. 308, 314, 1972.

126. DUARTE, John W. The future of the guitarduo [Sérgio e Eduardo Abreu]. 
Guitar review, New York, n 31, p. 12-13, mai. 1969.

127. DUARTE, John W. The guitar music of South America. Music and Musicians International, London, v. 37, $\mathrm{n}^{\circ}$ 11, p. 19-22, jul. 1989.

128. DUARTE, John W. The Preludes of Villa-Lobos: some notes. Guitar International, v. 13, $\mathrm{n}^{\circ} 11$, p. 43, jun. 1985; v. 14, n 1, p. 41, ago. 1985.

129. 200 LP de Geraldo Ribeiro para os leitores de "Violão e Mestres" [Ascendino Theodoro Nogueira]. Violão e Mestres, São Paulo, [v.1], $\mathrm{n}^{\circ}$ 5, p. 62-[63], jun. 1966; [v. 1], n ${ }^{\circ}$ 6, p. 52, set. 1966.

130. ELMERICH, Luis. A entrevista: Manoel São Marcos. Jornal da Música, São Paulo, ano7, no 44, p. 8, 1984.

131. Estes são os que jogam no time de Armandinho. Urubumalandro, São Paulo, número especial, p. 5-6, ago. 1978.

132. Falleceu o maior violonista brasileiro; "Canhôto" foi o vencedor do concurso "O que é nosso". Folha da Manhã, São Paulo, ano 4, n' 1.210, p. 7, sábado, 8 set. 1928.

133. FERGUSON, Jim. Almeida, Ibsin \& Caryell. Guitar player, Saratoga, v. $20, n^{\circ} 2$, p. $10,1986$.

134. FERNANDES, Juvenal. O cartaz da semana. In: JACOMINO, Américo, "Canhoto". Abismo de rosas e grandes obras. São Paulo, Fermata do brasil, s.d., p. 13-14.

135. [FIGUEIREDO, Ernani de]. A voz de uma autoridade sobre o violão; extracto de uma conferencia que o saudoso maestro Ernani de Figueiredo ia fazer em Campos em 1917. O Violão, Rio de Janeiro, ano 1, $\mathrm{n}^{\circ} 3$, [p. 7-10], fev. 1929.

136. FISCHER, Paul. Brazilian travels. Classical guitar, Gateshead, v. 2, n. 6 , p. 25-28, 1984.

137. FRANÇA, Eurico Nogueira. La chitarra di Villa-Lobos. Notiziario tecnico professionale della Accademia della Chitarra Classica, Milano, v. $11, n^{\circ} 40$, p. $24,1980$.

138. Uma futura gloria do violão brasileiro; Ivonne Rebello. O Violão, Rio de Janeiro, ano 1, n 1 , [p. 15], dez. 1928.

139. Galeria de perfis [Brant Horta]. O Violão, Rio de Janeiro, ano $1, \mathrm{n}^{\circ} 3$, [p. 17-18], fev. 1929.

140. Galeria de perfis [Homero Alvares]. O Violão, Rio de Janeiro, ano $1, \mathrm{n}^{\circ}$ 2 [p. 13], jan. 1929.

141. Galeria de perfis [João Pernambuco]. O Violão, Rio de Janeiro, ano $1, \mathrm{n}^{\circ}$ 1, [p. 12], dez. 1928.

142. Galeria de perfis [Melchior Cortez]. O Violão, Rio de Janeiro, ano 1, $\mathrm{n}^{\mathrm{o}} 4$, [p. 13], mar. 1929.

143. Galeria de perfis. O Violão, Rio de Janeiro, ano I, $n^{\circ} 5$, (p. 11-12), abr. 1929. 
144. Gespräch mit dem Gitarristen Martin Müller. Musikblatt, v. 9, nº 75, p. 10-13, 1982.

145. GHELLI-SANTULIANI, Maurizio. Considerazioni sull'edizionea stampa dei Dodici Studi di Villa-Lobos. Il Fronimo, Milano, v. 11, n 45 , p. 6$13,1983$.

146. GIL, Luis Reyes. Ritmos brasileiros. In: DENYER, Ralph. Toque. op cit., p. 201.

147. GILARDINO, Angelo. La musica per chitarra nel secolo XX. Il Fronimo, Milano, ${ }^{\circ}$ 44, p. 17-23, 1982.

148. GILARDINO, Angelo. Per una rilettura dei "Douze Etudes" di Villa Lobos. Il fronimo, Milano, v. 15, n. 61, p. 11-30, 1987.

149. GLADSTONE, Ralph J. An interview with Heitor Villa-Lobos. Guitar Review, New York, $\mathrm{n}^{\circ} 21$, p. 13, 1957.

150. GORDON, Diane. Turibio Santos: bearing the torch for the Villa-Lobos legacy. Guitar player, Saratoga, v. 23, no 5, p. 82-90, 1989.

151. GRILO, Eustáquio. Folk tunes from Brazil. Guitar international, v. 18, $\mathrm{n}^{\circ} 4$, p. $33-35,1989 / 1990$; v. $18, \mathrm{n}^{\circ}$ 5, p. 38-39, 1989/1990; v. $18, \mathrm{n}^{\circ} 6$, p. 31-33, 1989/1990; v. 18, no 8, p. 33-35, 1989/1990; v. 18, no 9, p. 42-43, $1989 / 1990$; v. 18, no 10, p. 36-37, 1989/1990; v. 18, no 11, p. 34-35, 1989/ 1990 ; v. 18, n $^{\circ} 12$, p. $36-37,1989 / 1990$; v. 19 , no 1 , p. $32-33,1990 / 1991$; v. $19, n^{\circ} 2$, p. $20-21,1990 / 1991$; v. $19, n^{\circ} 3$, p. 22-23, 1990/1991.

152. GRIMES, David. The GFA contemporary music series, $n^{\circ} 4$ ("Obstinacy" by Laurindo Almeida). The Sounboard, Cypress, v. 15, n 4, p. 317-319, $1988 / 1989$.

153. Gitarre konkret: das Gitarren-Repertoire auf dem Prüfstand; Heitor VillaLobos: Préludes. Musikblatt, $\mathrm{n}^{\circ}$ 4, p. 38-48, 1989.

154. Guitarristen und nicht klassische Gitarristen: Interview mit Sergio Assad. Guitarre und Laute, Kassel, v. 10, n 6, p. 8-14, 1988.

155. [Gustavo Ribeiro]. O Violão, Rio de Janeiro, ano 1, n 9, [p. 23], out. 1929.

156. HARTMAN,Thomas. Book review: Heitor Villa-Lobos and the guitar/ Turibio Santos. Guitar International, v. 14, n 12, p. 50-51, 1985/1986.

157. HEINZL, Alberto Amendola. Como nasce um violão. Violão e Mestres, São Paulo, v. 1, n. 2, p. 4-21, ago. 1964.

158. HEINZL, Alberto Amendola. Oviolão sem misticismo. Violão e Mestres, v. $1, n^{\circ} 1$, p. 15-16, mar. 1964.

159. Heitor Villa-Lobos. Der Gitarrenfreund, Müchen, v. 11, n $\mathrm{n}^{\circ}$ 1/2, p. 2-3, 1960.

160. Heitor Villa-Lobos. L'arte chitarristica, v. 13, no 70/72, p. 11-13, 1959.

161. HELLER, Alfred. The one-world "style" of Villa-Lobos. Guitar review, $n^{\circ} 78$, p. 18-19, 1989.

162. Hermes Fontes, poeta do amor e da saudade... A Voz do Violão, Rio de 
Janeiro, ano 1, no 1, [p. 12-13], fev. 1931.

163. HIMMELHOCH, Seth. Modinha and valsa: new guitar transcriptions by Francisco Mignone. Guitar International, v. 14, no 11, p. 18-23, 1985/ 1986 ; v. 15, n $^{\circ} 3$, p. $36-41,1986 / 1987$.

164. HIROSHI, Hara. Analysis of guitar music; H.Villa-Lobos, Etudes n ${ }^{\circ} 10$, 11 and 12. The Gendai Guitar, Tokyo, n ${ }^{\circ}$ 50, p. 104-111, 1971.

165. A história começou com "Abismo de Rosas" [Américo Jacomino]. Jornal da Tarde, Suplemento Especial, São Paulo, 27 mai. 1989, p. 4.

166. HODEL, Brian. Antonio Carlos Jobim: guitar player. Classical guitar, Gateshead, v. 3, nº 7, p. 19-21, 1985.

167. HODEL, Brian. Antonio Carlos Jobim at Carnigie Hall (concert in review) Guitar review, New York, $n^{\circ} 62$, p. 35, 1985.

168. HODEL, Brian. Baden Powell. Guitar review, n 83, p. 1-7, 1990.

169. HODEL, Brian. Brazilian popular music and the classical guitar. Classical guitar, Gateshead, v. 1, no 5, p. 43-47, 1983.

170. HODEL, Brian. The Chôro. Guitar review, New York, nº 73, p. 31-34, 1988.

171. HODEL, Brian. Egberto Gismonti. Guitar review, New York, ${ }^{\circ}$ 63, p. 18, 1985.

172. HODEL, Brian. Grosse Fugue Villa-Lobos. Guitar review, New York, $\mathrm{n}^{\circ}$ 71, p. 14-22, 1987.

173. HODEL, Brian. The guitar in Latin America. Monthly or two-montly column, Guitar review, New York, nº 65, 1986.

174. HODEL, Brian. An interview with Carlos Barbosa-Lima. Classical Guitar, Cateshead, v. 1, n ${ }^{\circ}$ 5, p. 48-49, 1983.

175. HODEL, Brian. Interview with Luis Bonfá. Guitar, London, jun 1981, p. 19-22.

176. HODEL, Brian. Isaias Sávio, master teacher. Guitar review, New York, $\mathrm{n}^{\circ} 58, \mathrm{p} .18-21,1984$.

177. HODEL, Brian. Mehr als Bossa-Nova: die populäre Musik Brasiliens und die klassische Gitarre. Gitarre und Laute, Kassel, v. 6, nº 1, p. 50-53, 1984.

178. HODEL, Brian. Radamés Gnattali. Guitar review, New York, ${ }^{\circ} 66, p$. 13-22, 1986.

179. HODEL, Brian. Spotlight on Luiz Bonfá. Guitar review, New York, $\mathrm{n}^{\circ}$ 56, p. $1-7,1984$.

180. HODEL, Brian. Turíbio Santos (the guitar in Latin America). Guitar review, New York, $\mathrm{n}^{\circ} 70$, p. 37-38, 1987.

181. HODEL, Brian. Villa-Lobos and the guitar. Guitar review, New York, $\mathrm{n}^{\circ} 72$, p. $20-27,1988$.

182. HOLDEN, Stephen. Jobim and Bossa Nova (concerts in review). Guitar review, New York, $\mathrm{n}^{\circ}$ 72, p. 32, 1988. 
183. HOLSTON, Mark. A gentle genius of the guitar: Brazilian virtuoso Carlos Barbosa-Lima. Guitar International, v. 18, n 3, p. 14-18, 1989/1990.

184. HOLSTON, Mark. A gentle genius of the guitar: Brazilian virtuoso Carlos Barbosa-Lima has used his extraordinary talents to reshape the boundaries of the classical guitar's repertoire. Americas, v. 39, nº 4, p. 50-53, 1987.

185. HOMEM DE MELLO, Zuza. Violão brasileiro, acervo incomparável [Ronoel Simões]. O Estado de S. Paulo, São Paulo, ano 100, n 31.927 , p. 16, domingo, 15 abr. 1979.

186. O homem que não pode parar [Isaias Sávio]. Violão e Mestres, São Paulo, v. $2, n^{\circ} 7$, p. $2-13,1967$.

187. Homenagem a Isaias Sávio; o duo Vidal Medeiros - Nelson Cruz. Violão e Mestres, São Paulo, [v.1], n 2, p. 40-43, ago. 1964.

188. HOPMAN, David D. Some ideas on practicing Villa-Lobos' Etude $n^{\circ} 1$ in $\mathrm{E}$ minor. The Soundboard, Cypress, v. 8, n² 2, p. 88-91, 1981.

189. Icarahy Violão Club. O Violão, Rio de Janeiro, ano $1, \mathrm{n}^{\circ} 1,[\mathrm{p} .13]$, dez. 1928.

190. Icarahy Violão Club. O Violão, Rio de Janeiro, ano 1, n 2, [p. 34], jan. 1929.

191. As interpretes da canção brasileira: Jesy Barbosa. A Voz do Violão, Rio de Janeiro, ano $1, n^{\circ} 1$, p. 13, fev. 1931.

192. Os interpretes da canção brasileira [Ogarita dell'Amico]. A Voz do Violão, Rio de Janeiro, ano 1, n 3, p. 15-16, abr. 1931.

193. Os interpretes da canção brasileira [Stefana de Macedo]. A Voz do Violão, Rio de Janeiro, ano 1, n 2, p. 26-27, mar. 1931.

194. Intervista a Maria L. São Marcos. Notiziario tecnico profissio nale della Accademia della Chitarra Classica, Milano, v. 8, n 27, p. 34-35, 1977.

195. Intervista di Adriano Sebastiani a sergio e Odair Assad. Il Fronimo, Milano, v. 15, nº 61, p. 8-11, 1987.

196. Isaias Sávio. Violão e Mestres, São Paulo, [v.1], n 5, p. 7-13, 15, jun. 1966.

197. De Itajubá [Levino Albano da Conceição]. O Violão, Rio de Janeiro, ano $1, \mathrm{n}^{\circ} 10$, [p. 13], nov./dez. 1929.

198. JAFEE, Michael. Harmony in the solo guitar music of Heitor Villa-Lobos. Guitar review, New York, n² 29, p. 18-22, jun. 1966.

199. Jamil Anderáos - o artista. Violão e Mestres, São Paulo, [v.1], n 3, p. 31, mar. 1965 .

200. Jessé [Silva]: 1200 horas de "sereno". Violão e Mestres, São Paulo, v. 2 , $\mathrm{n}^{\circ} 9$, p. 39 , nov. 1968.

201. Jodacil Damasceno. Violão e Mestres, SãoPaulo, [v.1], n 4, p. 54-55, set. 1965.

202. José Ferreira Filho. Violão e Mestres, São Paulo, [v.1], nº 6, p. 11-13, set. 1966. 
203. João Pires Argollo. Violão e Mestres, São Paulo, v. 2, n 9, p. 37-38, nov. 1968.

204. José. de Oliveira. Queiroz. Violão e Mestres, São Paulo, [v.1], n 3, p. 51, mar. 1965.

205. José de Oliveira Queiroz. Violão e Mestres, São Paulo, v. 2, nº 9, [p. 65], nov. 1968.

206. José Rogerio und Jaime Torres: Gitare und Charango. Gitarre und Laute, Kassel, v. 4, no 3, p. 164-167, 1982.

207. Jubileu de ouro de Isaías Sávio; Festival mostrou violão em todos seus aspectos. Violão e Mestres, São Paulo, [v.1], n 5, p. 4-6, jun. 1966.

208. Julieta Correa Antunes e as "Princesas do Violão". Violão e Mestres, São Paulo, [v.1], no 5, p. 20-23, jun. 1966.

209. KELLY, Christine K. Villa-Lobos. Guitar player, Saratoga, v. 15, $\mathrm{n}^{0} 7$, p. 70-71, jul. 1981 .

210. Komposition und Improvisation sind Zwillingsschwestern. Interwiew mit Baden Powell. Gitarre und Laute, Kassel, v. 5, nº 4, p. 239-245, 1983.

211. KOPLEWITZ, Laura. Carlos Barbosa-Lima: transcriptionist, arranger, classical virtuoso. Guitar player, Saratoga, v. 17, no 4, p. 50-62, 1983.

212. KOTZIA, Eleftheria. A musician of the streets: a view of Heitor VillaLobos (1887-1959). Classical guitar, Gateshead, v. 6, n 6, p. 35-36, 1988.

213. KOZINN, Allan. The Assads: a duo triumphs in a world dominated by soloists. Guitar player, Saratoga, v. 21, n 12, p. 34-41, 1987.

214. KOZINN, Allan. Marcelo Kayath (the guitar on record). Guitar review, New York, $\mathrm{n}^{0}$ 71, p. 25, 1987.

215. KOZINN, Allan. Sergio Abreu: Brazilian classical master. Guitar player, Saratoga, v. 14, nº 7, p. 48-55, 1980.

216. [KUBRUSLY, Maurício]. Gilberto Gil. In: DENYER, Ralph. Toque, op. cit., p. 73.

217. [KUBRUSLY, Maurício]. João Gilberto. In: DENYER, Ralph. Toque. op. cit., p. 75.

218. [KUBRUSLY, Maurício]. Jorge Ben. In: DENYER, Ralph. Toque, op. cit., p. 74.

219. [LANCELLOTTI, Sílvio]. Baden Powell. In: DENYER, Ralph. Toque. op. cit., p. 1-3.

220. [LANCELLOTTI, Sílvio]. Canhoto. In: DENYER, Ralph. Toque. op. cit., p.89-91.

221. [LANCELLOTTI, Sílvio]. Dilermando Reis. In: DENYER, Ralph. Toque, op. cit., p. 145-147.

222. [LANCELLOTTI, Sílvio]. Dino das 7 cordas. In: DENYER, Ralph. Toque. op. cit., p. 65-67. 
223. [LANCELLOTTI, Sílvio]. Hélio Delmiro. In: DENYER, Ralph. Toque. op. cit., p. 129-131.

224. [LANCELLOTTI, Sílvio]. Heraldo do Monte. In: DENYER, Ralph. Toque. op. cit., p. 57-59.

225. [LANCELLOTTI, Sílvio]. Laurindo de Almeida. In: DENYER, Ralph. Toque. op. cit., p. 9.

226. [LANCELLOTTI, Sílvio]. Paulinho Nogueira. In: DENYER, Ralph. Toque. op. cit., p. 33-35.

227. [LANCELLOTTI, Sílvio]. Toquinho. In: DENYER, Ralph. Toque. op. cit., p. 17-19.

228. LAURIE, Jennifer. Egberto Gismonti. Classical guitar, Gateshead, v. 7, $n^{\circ} 2$, p. 24-25, 1988.

229. Laurindo Almeida: celebração dos setenta. The Soundboard, Cypress, v. $14, n^{\circ} 4$, p. $245-247,1987 / 198$.

230. LEAL, José de Sousa \& BARBOSA, Artur Luiz. João Pernambuco; arte de um povo. Rio de Janeiro, MEC e FUNARTE, 1982. 72 p.

231. LEIGH, James L. Isaías Sávio. Guitar news, Cheltenham, n 46, p. 10$12,1959$.

232. LEIROZ, Manuel. Americo Jacomino. A Cigarra, São Paulo, ano $3, \mathrm{n}^{\circ}$ 45, [p. 18], 30 jun. 1916.

233. LIMA, E. de. A guitarra, instrumento romanceiro. Revista brasileira de música, Rio de Janeiro, $\mathrm{n}^{\circ} 2$, p. 67, p. 1938.

234. LIMA, Rossini Tavares de. Estudo sobre a viola. Revista brasileira de folclore, Rio de Janeiro, v. 4, nos. 8/10, p. 29-38, jan./dez. 1964.

235. LIMA, Rossini Tavares de. Música folclórica e instrumentos musicais do Brasil. Boletín Interamericano de Música, Washington, $n^{\circ} 49$, p. 3-22, set. 1975.

236. LOPES, Antonio Fernando. Esses ocultos precursores [Garoto]. Folha de S. Paulo, Ilustrada, São Paulo, ano $65, \mathrm{n}^{\circ} 20.745,9^{\circ}$ caderno, p. 83, domingo, 19 jan. 1986.

237. LOPES, Fernanda Guimarães. No velho Bixiga, violão tem museu e academia [Ronoel Simões]. Diário Popular, São Paulo, ano 97, $\mathrm{n}^{\circ} 31.688$, p. 11, domingo, 11 out. 1981.

238. LORIMER, Michael. Damping and Villa-Lobos' Prelude $n^{\circ} 4$. Guitar player, Saratoga, v. 13, n 10, p. 150, 1979.

239. LORIMER, Michael. Villa-Lobos: Prelude $n^{\circ} 1$; an analysis. Guitar player, v. 15, nº 7, p. 71-72, jul. 1981.

240. Lourival Montenegro e a sua criatividade artistica. A Voz do Violão, Rio de Janeiro, ano 1, $n^{\circ}$ 3, p. 27-28, mar. 1931.

241. MAGRI, Roberto. La musica per chitarra sola di Heitor Villa-Lobos. Torino, UNIVERSITÀ DEGLI STUDI DI TORINO, Tesi di Laurea, 
Anno Accademico 1983-1984.

242. MAGYAR, Vera. A Musa: aos 93 anos, dona Laura das Dores lembra do tempo em que inspirou o Abismo de Rosas, de Canhoto. Jornal da Tarde, São Paulo, 10 out. 1978, p. 15.

243. MAI, Daniel. Maria Livia São Marcos: classical brightest new star. Guitar player, Saratoga, v. 10, nº 1, p. 12, 41, 42, 1976.

244. MAIER, Peter. Duo Assad. Guitarre aktuell, Hamburg, v. 9, nº 33, p. 2324, 1988.

245. MAIER, Peter. Eine Reise nach Brasilien. Guitarre aktuell, Hamburg, v. 11, no 37, p. 5-16, 1990.

246. MAIRANTS, Ivor. Paulino Bernabé. B.M.G., London, nov. 1973, p. $2-$ 3.

247. MANZANARES, Sheilei. José Lopes. Violão e Mestres, São Paulo, v. 2 , $n^{\circ} 9$, p. 42, nov. 1968.

248. Mara, a concertista de 8 anos de idade. Violão e Mestres, São Paulo, [v.1], $n^{\circ} 1$, p. 9, mar. 1964.

249. Marcelo Kayath, Brazilian guitarrist, 1984 winner in both Toronto and Paris: in conversation with Mary Criswick. The Soundboard, Cypress, v. 13, nos. 3/4, p. 199-201, 1986/1987.

250. Marcelo Kayath. Nova Giulianad, Freiburg i.Br., v. 2, nº 7, p. 205, 1985.

251. Marcelo Kayath: on preparing for competitions; interview by James Wilson. Classical guitar, Gateshead, v. 3, nº 6, p. 25-26, 1985.

252. Maria Livia [São Marcos] na Europa. Violão e Mestres, São Paulo, [v.1], $\mathrm{n}^{\circ}$ 2, p. 38, ago. 1964.

253. Maria Lívia [São Marcos]: a ex-menina-prodígio. Violão e Mestres, São Paulo, [v.1], nº 6, p. 49-51, set. 1966.

254. 'Maria Livia São Marcos. Violão e Mestres, São Paulo, [v.1], n 1, p. 2829, mar. 1964.

255. [MASTRANGELO, Felicio]. A voz do violão transmitida pelo radio. $A$ Voz do Violão, Rio de Janeiro, ano 1, n ${ }^{\circ} 1$, p. 28, fev. 1931.

256. [MASTRANGELO, Felicio]. A voz do violão transmitida pelo radio. A Voz do Violão, Rio de Janeiro, ano 1, n 2, p. 30, mar. 1931.

257. MEGANTZ, Bob. Suguiyama: Brazilian luthier extraordinaire. The Soundboard, Cypress, v. 15, no 3, p. 199-201, 1988.

258. MELHOR, Anísio. Violas: contribuição ao estudo do folk-lore bahiano. Bahia, Imprensa Vitória, 1935. 171 p.

259. MELO, Veríssimo de. Cantador de viola. Recife, Imprensa Oficial, 1961. 86 p. (Coleção Concórdia).

260. Memória viva do violão brasileiro [Ronoel Simões]. Jornal da Tarde, Suplemento Especial, São Paulo, 27 mai. 1989, p. 2.

261. O mestre [Quincas Laranjeira, Oswaldo Teixeira e Manoel Móra]. O 
Violão, Rio ae Janeiro, ano 1, n 1, [p. 23], dez. 1928.

262. Os mestres do violão. Correio da manhã, Rio de Janeiro, 12 dez. 1926, p. 11.

263. MONTANARO R., Bruno. Guitares hispano-americaines. Aix-enProvence, Edisud, 1983. 184 p.

264. MONTEIRO, Léa Zigiatti. Gente jovem para aplicar didática nova ao violão. Violão e Mestres, São Paulo, [v.1], nº 6, p. 18-20, set. 1966.

265. MOSER, Wolf. Verloren - gefunden: Heitor Villa-Lobos und sein Werk. Musikblatt, v. 14, $\mathrm{n}^{\circ} 118$, p. 13-19, 1987.

266. MOTA, Leonardo. Violeiros do Norte; prefácio de Hermann Lima. 4a., Rio de Janeiro, Cátedra; Brasília, INL, 1976. lviii, 259 p.

267. MÜLLER, Martin. Neues aus der Brasilianischen Gitarrenszene: Martin Müller spielte und reiste 6 Wochen durch Brasilien. Guitarre und Laute, Köln, v. 12, nº 6, p. 51-52, 1990.

268. Muricy [Adjacy Sampaio] em São José dos Campos. Violão e Mestres, São Paulo, v. 2, nº 8, p. 31-34, dez. 1967.

269. O músico Attilio Bernardini. Violão e Mestres, São Paulo, v. 2, n 8, p. 20-25, dez. 1967.

270. Na cidade um rico acervo sobre Américo Jacomino, o Canhoto. Jornal de Jundiai, Regional, Jundiaí, 7 jan. 1979, p. 7.

271. Nasce o violão... e o violonista [Shiguemitsu Suguiyama e Rafael Rabello]. Jornal da Tarde, Suplemento Especial, São Paulo, 27 mai. 1989, p. 3.

272. NASCIMENTO, Tiberio. Bossa nova. Guitar International, v. $14, \mathrm{n}^{\circ} 2$, p. 18 , set. 1985 .

273. NASSIF, Luis. Toque de mestre; um modesto registro da obra do grande Garoto. Veja, São Paulo, n 551, p. 77-78, mar. 1979.

274. Nelson Martins Cruz. Violão e Mestres, São Paulo, [v.1], n 4, p. 55, set. 1965.

275. NEVES, Armando. O violão no tempo de Canhoto; o conhecido compositor Armandinho fala da época de ouro das serenatas. Violão e Mestres, São Paulo, [v.1], n 1, p. 20-23,

276. NEVES, José Maria. Villa-Lobos; o choro e os choros. São Paulo, Ricordi, 1980. 140 p.

277. Nicanor [Teixeira] diz que o Rio tem mais sonho e mais poesia. Violão e Mestres, São Paulo, [v.1], n 4, p. 28-29, set. 1965.

278. NOGUEIRA, Ascendino Theodoro. Anotações para um estudo sobre a viola: origem do instrumento e sua difusão no Brasil. A Gazeta, São Paulo, ano 58, n 17.469, p. 22, sábado, 24 ago. 1963.

279. Uma noite de arte ligeira, no Instituto Nacional de Musica [Olga Praguer]. $O$ Violão, Rio de Janeiro, ano 1, n 2, [p. 5-6], jan. 1929.

280. Uma noite de arte em Nictheroy. O Violão, Rio de Janeiro, ano $1, \mathrm{n}^{\circ} 3$, [p. 33], fev. 1929. 
281. Uma noite brasileira no Tijuca Tennis Club. O Violão, Rio de Janeiro, ano $1, \mathrm{n}^{\circ} 1$, [p. 27], dez. 1928.

282. Noites de arte [Olga Praguer]. O Violão, Rio de Janeiro, ano 1, n ${ }^{\circ}$, [p. 27], out. 1929.

283. As noites de musica brasileira. O Violão, Rio de Janeiro, ano $1, \mathrm{n}^{\circ} 3,[\mathrm{p}$. 19], fev. 1929.

284. As "noites de violão" nas Fôlhas. Violão e Mestres, São Paulo, v. 2, n 8, p. 54-56, dez. 1967.

285. Notas violonísticas [Américo Jacomino, Sociedade Cultural do Violão, Antonio Carlos Barbosa-Lima, Paulinho Nogueira]. Violão e Mestres, São Paulo, [v.1], nº 6, p. 59-61.

286. Notas violonísticas [Antonio Carlos Barbosa-Lima]. Violão mestres, São Paulo, [v.1], n 1, p. 34, mar. 1964.

287. Notas violonísticas [Carlos Iafelice, Isaias Sávio, Antonio Carlos Barbosa Lima e Paulinho Nogueira]. Violão e Mestres, São Paulo, [v.1], $\mathrm{n}^{\circ} 3$, p. 50, mar. 1965.

288. Notas violonísticas [José Augusto de Freitas e Sylvio Serpa]. Violão e Mestres, São Paulo, [v.1], nº 6, p. 61, set. 1966.

289. Notas violonísticas [Sociedade Cultural doViolão]. Violão e Mestres, São Paulo, v. 2, no 9, p. 64, nov. 1968.

290. Notas violonísticas [Sérgio e Eduardo Abreu]. Violão e Mestres, São Paulo, [v.1], n² 2, [p. 55], ago. 1964.

291. Notas violonísticas [Maria Livia São Marcos, Turibio Santos, Noites de Violão nas Folhas, Antonio Carlos Barbosa Lima, Isaías Sávio]. Violão e Mestres, São Paulo, [v.1], nº 5, p. 60-61, jun. 1966.

292. Olga Pragner [Coelho]. O Violão, Rio de Janeiro, ano 1, nº 4, [p. 31], mar. 1929.

293. OLIVEIRA JUNIOR, Diógenes de. Violão brasileiro, 80 anos: técnicas e ritmos, estudo didático-pedagógico moderno. Paulínea, Prefeitura Municipal, $1981.193 \mathrm{p}$.

294. Osvaldo Soares. Violão e Mestres, São Paulo, [v.1], nº 5, p. 49, jun. 1966.

295. Othon Saleiro; ciência e arte em Campinas: I Semana do Folclore. Violão e Mestres, São Paulo, [v.1], nº 2, p. 54, ago. 1964.

296. PÄFFGEN, Peter. Eine neue Dimension! Sergio und Odair Assad setzen Masstäbe. Gitarre und Laute, Kassel, v. 10, n 1, p. 30-31, 1988.

297. Palavras de ouro; a opinião da Sra. Flavio da Silveira sobre nossa musica regional; por que não temos uma cadeira de violão no Instituto Nacional de Musica? O Violão, Rio de Janeiro, ano 1, n 2, [p. 18-19], jan. 1929.

298. Paulinho [Nogueira]: o violão sem limitaç̃̃es. Violão e Mestres, São Paulo, v. 2, nº 9, p. 2-8, nov. 1968.

299. PEEL, Douglas. Heitor Villa-Lobos: 1887-1959. B.M.G., London. v. 69 , 
n 795 , p. 340, 1971.

300. PENALVA, Gastão. A lenda do violão. A Voz do Violão, Rio de Janeiro, ano $1, n^{\circ} 3$, p. 13-14, mar. 1931.

301. PENALVA, Gastão. O Violão. O Violão, Rio de Janeiro, ano 1, n 7, [p. 8-9], jul. 1929.

302. PENNA, Mauro. O violão clássico no Brasil. Revista Acorde, São Paulo, v. $1, n^{\circ} 6$, p. $734-736,1986$.

303. PEREIRA, Marco. Heitor Villa-Lobos: sua obra para violão. Brasília, Musimed, 1984. $112 \mathrm{p}$.

304. Perfis. O Violão, Rio de Janeiro, ano 1, nº 6, [p. 12], mai./jun. 1929.

305. PERON, Italo \& MOURA, Paulo C. A concepção harmônica e melódica em Jorge do Fusa, de Garoto. Cadernos de Estudo: Análise Musical, São Paulo, n 3 , p. 20-26, out. 1990.

306. Programa oficial dos cursos de violão nos conservatórios; publicado por "Violão e Mestres" de acôrdo com o original fornecido pelo Prof. Isaías Sávio. Violão e Mestres, São Paulo, [v.1], nº 5, p. 27-34, jun. 1966.

307. O proximo concerto do Prof. João Pereira. O Violão, Rio de Janeiro, ano 1, no 9, [p. 35], out. 1929.

308. O que é nosso. O Violão, Rio de Janeiro, ano 1, $\mathrm{n}^{\circ}$ 5, [p. 15], abr. 1929. 309. O que é nosso. O Violão, Rio de Janeiro, ano 1, n 5, [p. 22], abr. 1929. 310. O queé nosso. O Violão, Rio de Janeiro, ano 1, nº 6, [p. 13], mai./jun. 1929. 311. O que é nosso; o "Correio da Manhã" proseguirá na defesa do nosso patrimonio. O Violão, Rio de Janeiro, ano 1, $\mathrm{n}^{\circ}$ 5, [p. 18-19], abr. 1929.

312. Noite de Violão nas Fôlhas. Violão e Mestres, v. 2, nº 6, p. 43, set. 1966.

313. RAMOS, Clovis \& MARTINS, Guimarães. Violão ao luar e vulcões de flores; Catulo da Paixão Cearense e Correia de Araujo. Rio de Janeiro, Edição do Grêmio Cultural Catulo da Paixão Cearense, 1974.

314. Raquel Taboada; violão e poesia. Violão e Mestres, São Paulo, [v.1], n 3, p. 35, mar. 1965

315. [REBELLODA SILVA, José]. Diz que não foi... O Violão, Rio de Janeiro, ano $1, \mathrm{n}^{\circ}$ 5, [p. 25], abr. 1929.

316. Recital de canções ao violão [Helena de Magalhães Castro]. O Violão, Rio de janeiro, ano 1, n 6, [p. 22], mai./jun. 1929.

317. Recital da Escola Livre de Violão "Isaias Sávio". Violão e Mestres, São Paulo, [v.1], n², p. 53, ago. 1964.

318. Recital Medeiros/Iafelice. Violão e Mestres, São Paulo, [v.1], nº 4, p. 5657 , set. 1965.

319. Recital de violão [Olga Praguer]. O Violão, Rio de Janeiro, ano $1, n^{\circ} 8$, [p. 11], ago./set. 1929.

320. Recital de violão de José de Freitas. O Violão, Rio de Janeiro, ano $1, \mathrm{n}^{\circ}$ 8, [p. 14-15], ago./set. 1929. 
321. Recital de violão de Maria Livia São Marcos. Violão e Mestres, São Paulo, [v.1], no 2, p. 51, ago. 1964.

322. As reminiscencias de um velho palhaço; "Gadanha", gloria antiga dos picadeiros de circo. A Voz do Violão, Rio de Janeiro, ano $1, \mathrm{n}^{\circ}$ 3, p. 30, abr. 1931.

323. Renato Murce; o que nos disse o popular cantor. A Voz do Violão, Rio de Janeiro, ano 1, $\mathrm{n}^{\circ} 2$, p. 19-20, mar. 1931.

324. RESNICOFF, Matt. ToninhoHorta: Brazilian rhythm ambassador. Guitar player, Saratoga, v. 24, $\mathrm{n}^{\circ} 1$, p. 54-60, 1990.

325. A revista "O Violão". Violão e Mestres, São Paulo, [v.1], n 4, p. 4-11, set. 1965.

326. The roots are popular: Turibio Santos interviewed by Mayes and Colin Cooper. Classical guitar, Gateshead, v. 3, nº 4, p. 13-16, 1984.

327. Samuel Babo e a A.B.V. Violão e Mestres, São Paulo, [v.1], nº 4, p. 2427 , set. 1965 .

328. SANTOS, Turíbio. Heitor Villa-Lobos e o violão. Rio de Janeiro, Museu Villa-Lobos, 1975. $61 \mathrm{p}$.

329. SÃO MARCOS, Manuel. Camerata violonística. Jornal da música, São Paulo, ano 6, n 4l, p. 4, nov./dez. 1983.

330. SÃO MARCOS, Maria Lívia. Primeiro curso de violão em Aracajú. Violão e Mestres, São Paulo, v. 2, n 7, p. 22-24, 1967.

331. São Marcos [Manuel]: uma vida dedicada ao violão. Violão e Mestres, São Paulo, v. 2, no 8, p. 2-10, dez. 1967.

332. SÁVIO, Isaías. Antonio Rebello. Violão e Mestres, São Paulo, [v.1], ${ }^{\circ}$ 5, p. 35-38, jun. 1966.

333. SÁVIO, Isaías. Aos violonistas de São Paulo. Violão e Mestres, São Paulo, [v.1], n 2, p. 39, ago. 1964.

334. SÁVIO, Isaías. Quincas Laranjeira. Violão e Mestres, São Paulo, [v.1], $\mathrm{n}^{\circ}$ 4, p. 48-49, set. 1965.

335. SÁVIO, Isaías. Souza Lima [Lourivai A ugusto de]. Violão e Mestres, São Paulo, v. 2, no 9 , p. 36, nov. 1968.

336. SÁVIO, Isaías. Violão: Tábua cronológica (1784-1910); compilação de Isaías Sávio (conclusão do numero anterior). Violão e Mestres, São Paulo, v. $2, \mathrm{n}^{\circ} 9$, p. $44-51$, nov. 1968.

337. SCARLATTI, Vincenzo. Clasicos Antiguos. Guitarra, Chicago, v. $5, \mathrm{n}^{\circ}$ 26, p. 18-19, mai.jun. 1967.

338. SCHAFFER, John W. The idée fixe in the solo guitar music of Heitor Villa-Lobos. The Soundboard, Cypress, v. 7, nº 2, p. 56-58, 1980.

339. SCHAFFER, John W. The published solo guitar music of Heitor VillaLobos. MA diss., Music: Southeastern Community College.

340. SCHAFFER, John W. Villa-Lobos: elusive 6th Prelude. Guitar and lute, 
Honolulu, $\mathrm{n}^{\circ} 15$, p. 32-33, 1980.

341. SCHAFFER, John W. Voice leading: towards a better understanding of select passages in Villa-Lobos "Preludes for Guitar". The Soundboard, Cypress, v. 7, n 4, p. 155-159, nov. 1980.

342. SCHÖNFELD, Evelyne. Heitor Villa-Lobos: Vorkämpfer brasilianischer Musik; zum Gedenken am 15. Todestage. Zupfmusik-Gitarre, Reutlingen, v. $27, \mathrm{n}^{\circ} 4$, p. $116,1974$.

343. SCHWARZ, Fritz. Heitor Villa-Lobos: 1887-1987; Gedanken zu seinen Gitarren-Kompositionen. Zupfmusikmagazin, v. 41, n³ 3, p. 83-84, 1988.

344. SCOTT, John. Oscar Castro-Neves: guitarrist, arranger, Bossa Nova inovator. Guitar plaver, Saratoga, v. 15, n 6, p. 40-47, 92, 1981.

345. Scupinari [Alfredo]: o mestre proficuo. Violão e Mestres, São Paulo, [v.1], $\mathrm{n}^{\circ}$ 2, p. 35-38, ago. 1964.

346. SEGOVIA, Andrés. Heitor Villa-Lobos. Ritmo, Madrid, $\mathrm{n}^{\circ} 418$, jan./fev. 1972.

347. SEGOVIA, Andrés. I met Villa-Lobos. Guitar review, New York, $n^{\circ} 22$, p. 22-23, 1958.

348. SENSIER, Peter. Eduardo Abreu. In: SADIE, Stanley (ed.). The new Grove dictionary of music and musicians. London, Macmillan Publ. Lim.; Washington, Grove's Dictionaries of Music; Hong Kong, Peninsula Publ. Lim., 1980. v. 1, p. 24.

349. SENSIER, Peter. Sérgio Abreu. In: SADIE, Stanley (ed.). The new Grove dictionary of music and musicians. op. cit., v. 1, p. 24.

350. Sergio Abreu vence o concurso de Paris. Violão e Mestres, São Paulo, v. 2, no 8, p. 44-45, dez. 1967.

351. Sérgio e Eduardo [Abreu] em São Paulo. Violão e Mestres, São Paulo, v. 2, $\mathrm{n}^{\circ} 7$, p. 30-32, 1967.

352. [SILVA, Rossini]. De Bahia (especial para "O Violão”). O Violão, Rio de Janeiro, ano 1, n 10, [p. 29], nov./dez. 1929.

353. SIMÕES, Ronoel. Américo Jacomino Canhoto (1887-1928): un grande chitarrista Brasiliano. L'arte chitarristica, Modena, v. 3, n 17, p. 3, 1949.

354. SIMÕES, Ronoel. Américo Jacomino, "Canhoto". In: JACOMINO, Américo. Abismo de rosas e grandes obras. São Paulo, Fermata doBrasil, s.d., p. 5-9.

355. SIMÕES, Ronoel. Américo Jacomino, o"Canhoto". Violão e Mestres, São Paulo, [v.1], n 1, p. 4-8, mar. 1964; v. 1, n² 2, p. 24-28, ago. 1964.

356. SIMÕES, Ronoel. Concurso Internacional de Violão [Darcy Vila Verde]. Violão e Mestres, São Paulo, [v.1], n 5, p. 43-45, jun. 1966.

357. SIMÕES, Ronoel. The guitar in Brazil; transl. and ed. by Eithne Golden. Guitar review, New York, n 22, p. 6-7, 1958.

358. SIMÕES, Ronoel. O violão. A Gazeta, São Paulo, ano 48, n 14.587, p. 
2, quinta-feira, 21 jan. 1954.

359. SIMÕES, Ronoel. Violão em discos [Ascendino Theodoro Nogueira e Geraldo Ribeiro]. Violão e Mestres, São Paulo, v. 2, nº 7, p. 33-37, 1967.

360. SIMÕES, Ronoel. Violão em discos [Antonio Carlos Barbosa Lima]. Violão e Mestres, São Paulo, [v.1], nº 5, p. 53-54, jun. 1966.

361. SIMÕES, Ronoel. Violão em discos [Luís Bonfá]. Violão e Mestres, São Paulo, v. 2, no 9, p. 56-58, nov. 1968.

362. SIMÕES, Ronoel. Violão em discos [Paulinho Nogueira]. Violão $e$ Mestres, São Paulo, v. 2, nº 8, p. 57-58, dez. 1967.

363. SIMÕES, Ronoel. Oviolão no Rio de Janeiro. Violão e Mestres, São Paulo, [v.1], no 4, p. 44-45, set. 1965.

364. SIMÕES, Ronoel. O violão em São Paulo. Violão e Mestres, São Paulo, v. $2, \mathrm{n}^{\circ} 7$, p. $25-29,1967$.

365. Sinhô. $A$ Voz do Violão, Rio de Janeiro, ano 1, nº 3, p. 20-21, mar. 1931.

366. SIQUEIRA, Ethevaldo. Isaias Savio, acima de tudo, o mestre. O Estado de S. Paulo, São Paulo, ano 98, n 31.241, p. 18, domingo, 23 jan. 1977.

367. SOARES, Francisco das Chagas. O violão no Brasil. Jornal da música, São Paulo, v. 7, n 43, p. 5, 1984.

368. [SOARES, Oswaldo]. Violão. Diário Nacional, São Paulo, ano 5, $\mathrm{n}^{\circ} 1.507$, p. 4, 7 jul. 1932.

369. [SOARES, Oswaldo]. O violão em S. Paulo. O Violão, Rio de Janeiro, ano 1, no 3, [p. 11-13], fev. 1929.

370. [SOARES, Oswaldo]. O violão em São Paulo. O Violão, Rio de Janeiro, ano $1, n^{\circ} 6,[p .14-15]$, mai./jun. 1929.

371. [SOARES, Oswaldo]. O violão em São Paulo. O Violão, Rio de Janeiro, ano $1, n^{\circ}$ 9, [p. 6-7], out. 1929.

372. Sôbre Milton Nunes. Violão e Mestres, São Paulo, [v.1], n 6, p. 14-17, 1966.

373. À sombra de Pixinguinha (mas tão bons quanto eles). Jornal da Tarde, São Paulo, 12 jul. 1979.

374. STEWART, Jimmy. The guitarrist as a complete musician: Heitor VillaLobos. Guitar player, Saratoga, v. 8, n 6, p. 61, jun. 1974.

375. STOVER, Richard D. Guitar in Latin America. Guitar player, Saratoga, v. 9, n. 7 , p. $18,30,32,35,36,39$, jul. 1975.

376. STOVER, Richard D. Guitarra Americana. The Soundboard, Cypress, v. $9, \mathrm{n}^{\circ} 2$, p.150-152, 1982; v. $9, \mathrm{n}^{\circ} 3$, p. 261-265, 1982; v. $10, \mathrm{n}^{\circ} 1$, p. $81-$ 86,1983 ; v. $10, n^{\circ} 2$, p. $166-169,1983$; v. 10 , no 3 , p. $273-275$, 1983 ; v. $10, n^{\circ} 4$, p. $390-393,1983$; v. 11 , no 1 , p. $55-62,1984$; v. 11 , n 2 , p. $164-$ 174,1984 ; v. 11, no 4, p. 371-375, 1984; v. 12, no 1, p. 86-89, 1985.

377. Sucesso no exterior: Sérgio e Eduardo Rebêllo Abreu. Violão e Mestres, São Paulo, [v.li, no 5, p. 52, jun. 1966. 
378. Taking the floor: Everton Gloeden in conversation with Chris Kilvington. Classical guitar, Gateshead, v. 8, $\mathrm{n}^{\circ} 1$, p. 16-17, 1989.

379. Uma tarde artística no Theatro Casino [Olga Praguer]. O Violão, Rio de Janeiro, ano 1, $\mathrm{n}^{\circ}$ 10, [p. 11-12], nov./dez. 1929.

380. THOMÉ, Nadra Michel. O violão de Romeo di Giorgio. Jornal da Tarde, Suplemento Especial, São Paulo, 27 mai. 1989, p. 7.

381. [TIGRE, Bastos]. Como os nossos intellectuaes apreciam o violão. $A$ Voz do Violão, Rio de Janeiro, ano 1, n 2, p. 21-23, mar. 1931.

382. Tijuca Tennis Club. O Violão, Rio de Janeiro, ano 1, nº 2, [p. 35-38], jan. 1929.

383. TINHORÃO, José Ramos. Surpresa é o som da viola de Tião Carreiro. Jornal do Brasil, Rio de Janeiro, 21 jul. 1976.

384. TINHORÃO, José Ramos. Vamos conhecer Tião Carreiro e Pardinho enquanto é tempo. Jornal do brasil, Rio de Janeiro, 15 jul. 1975.

385. O triumpho do violão. O Estado de S. Paulo, São Paulo, ano 53, $\mathrm{n}^{\circ} 17.784$, p. 4, col. A Sociedade, terça-feira, 29 nov. 1927.

386. Turibio [Santos]. Violão e Mestres, São Paulo, [v.1], n 4, p. 21-23, set. 1965.

387. Turibio Santos. The Guitar Society of Toronto bulletin, Toronto, set. 1980 , p. 1.

388. Turibio Santos. Violão e Mestres, São Paulo, [v.1], n 5 , p. 18-19, jun. 1966.

389. Turibio [Santos]: responsabilidade de vencedor começa depois. Violãoe Mestres, São Paulo, [v.1], nº 6, p. 32-36, set. 1966.

390. VERDERY, Benjamin. Villa-Lobos' multi-faced "Etude $n^{\circ} 1$ ". Guitar player, Saratoga, v. 24, nº 9, p. 106-107, 1990.

391. The Villa-Lobos guitar. Guitar news, Cheltenham, $n^{\circ} 72$, p. 6-8, 1963.

392. Viola brasileira, folclórica ou caipira ingressa amanhã no Teatro Municipal, em concêrto comemorativo ao mês do folclore. A Gazeta, São Paulo, ano 58, n 17.469, sábado, 24 de agosto de 1963, p. 11.

393. O violão. O Estado de S. Paulo, São Paulo, ano 53, n ${ }^{\circ} 17.785$, p. 5, col. A Sociedade, quarta-feira, 30 nov. 1927.

394. O violão através dos séculos. O Violão, Rio de Janeiro, ano $1, n^{\circ} 1$, [p. 57], dez. 1928.

395. O violão na Bahia. O Violão, Rio de Janeiro, ano 1, $\mathrm{n}^{\circ}$ 9, [p. 10], out. 1929. 396: "O Violão" na Bahia [Rossini Silva]. O Violão, Rio de Janeiro, ano $1, \mathrm{n}^{\circ}$ 9, [p. 17], out. 1929.

397. Violão em discos. O Violão, Rio de Janeiro, ano 1, no 1, [p. 22], dez. 1928.

398. O violão entre nós. O Violão, Rio de Janeiro, ano 1, n 1, [ p. 10-11], dez. 1928.

399. O violão nos Estados [Luiz Giordano]. A Voz do Violão, Rio de Janeiro, 
ano $1, \mathrm{n}^{\circ} 1, \mathrm{p} .17-18$, fev. 1931.

400. O violão nos Estados [Mario Mello e Mozart Bicalho]. A Voz do Violão, Rio de Janeiro, ano 1, n 3, p. 25-26, abr. 1931.

401. O violão nos Estados [Rosinha de Pinheiro Lima e Aracy Faria]. A Voz do Violão, Rio de Janeiro, ano 1, $\mathrm{n}^{\circ}$ 2, p. 13, mar. 1931.

402. Violão e mestres no Canal 2. Violão e Mestres, v. 1, nº 1, p. 31, mar. 1964.

403. Violão e mestres no Canal 4. Violão e Mestres, São Paulo, [v.1], $\mathrm{n}^{\circ}$ 3, p. 40-41, mar. 1965.

404. O violão mal interpretado. O Violão, Rio de Janeiro, ano $1, \mathrm{n}^{\circ} 6$, [p. 26], mai./jun. 1929.

405. O violão no Rio Grande do Sul [Miguel Olivé Leite]. O Violão, Rio de Janeiro, ano 1, n 9, [p. 8], out. 1929.

406. O violão nas sociedades de radio. O Violão, Rio de Janeiro, ano $1, \mathrm{n}^{\circ} 1$, [p. 22], dez. 1928.

407. O violão em S. Paulo [Francisco e Aristodemo Pistoresi, Oswaldo Soares e Yvonne Daumerie]. O Violão, Rio de Janeiro, ano 1, n 2, [p. 26-27], jan. 1929.

408. O violão em S. Paulo [Oswaldo Soares]. O Violão, Rio de Janeiro, ano 1 , $\mathrm{n}^{\circ}$ 8, [p. 18], ago./set. 1929.

409. O "Violão" em São Paulo [Walter Kneesse]. O Violão, Rio de Janeiro, ano $1, \mathrm{n}^{\circ}$ 7, [p. 29], jul. 1929.

410. De violão e suas cordas. Violão e Mestres, São Paulo, [v.1], n ${ }^{0} 3$, p. 1323, mar. 1965.

411. O violão de Tranquillo Giannini. Jornal da Tarde, Suplemento Especial, São Paulo, 27 mai. 1989, p. 6.

412. O Violão é uma esplendida revista. O Violão, Rio de Janeiro, ano $1, \mathrm{n}^{\circ} 9$, [p. 8], out. 1929.

413. Violão e viola em 64 [Antonio Carlos Barbosa Lima]. Violão e Mestres, São Paulo, [v.1], n 3, p. 12, mar. 1964.

414. O violeiro. Veja, São Paulo, no 479, p. 94, nov. 1977.

415. Violeiros. João Pessoa, Secretaria de Divulgação e Turismo, 1983. 7 p.

416. Violões Giannini na Polônia. Violão e Mestres, São Paulo, v. 2, no 8, p. 42-43, dez. 1967.

417. Violões Giannini nos Estados Unidos. Violão e Mestres, v. 1, n 4, p. 4648, set. 1965.

418. Um violonista do Norte [José de Oliveira Queiroz]. Violão e Mestres, v. $1, \mathrm{n}^{\circ} 1$, p. 23, mar. 1964.

419. VITTA, Oswaldo Luiz. Um disco só de Armandinho. Urubumalandro, São Paulo, número especial, p. 3, ago. 1978.

420. A volta do violão nos anos 70 , com o velho chorinho e os novos chorões. Jornal da Tarde, Suplemento Especial, São Paulo, 27 mai. 1989, p. 5. 
421. A Voz do Violão gravada em discos. A Voz do Violão, Rio de Janeiro, ano $1, \mathrm{n}^{\circ} 1$, p. 22-23, fev. 1931.

422. A Voz do Violão gravada em discos. A Voz do Violão, Rió de Janeiro, ano $1, \mathrm{n}^{\circ}$ 2, p. 7, mar. 1931.

423. A Voz do Violão gravada em discos. A Voz do Violão, Rio de Janeiro, ano $1, n^{\circ} 3$, p. 28-29, abr. 1931.

424. A Voz do Violão transmittida pelo radio. A Voz do Violão, Rio de Janeiro, ano $1, \mathrm{n}^{\circ} 1, \mathrm{p} .28$, fev. 1931.

425. A Voz do Violão transmitida pelo radio. A Voz do Violão, Rio de Janeiro, ano $1, n^{\circ} 2$, p. 29-30, mar. 1931.

426. WADDEY, Halph C. Samba de viola e viola de samba no recôncavo baiano. Salvador, Centro de Estudos Afro-Orientais, 1980. 16 p. (Ensaios, Pesquisas, v. 6).

427. WADDEY, Halph C. Viola de samba and samba de viola in the reconcavo of Bahia (Brazil). Revista de música latino americana, Austin, v. 1, $\mathrm{n}^{\circ}$ 2, p. 196-812, fall/winter 1980; v. 2, n 2, p. 252-279, fall/winter 1981.

428. WADE, Graham. Villa-Lobos, his magical art. Guitar news, Cheltenham, $n^{\circ} 96$, p. 6-8, 1967.

429. WURMBAUER, Hans. Isaias Savio. Gitarre, Wall in Bayern, v. 8, $\mathrm{n}^{\circ} 2$, p. $4,1977$.

430. ZALKOWITSCH, Gennady. Radamés Gnattali: the eternal experimenter. Classical guitar, v. 9, n² 2, p. 18-22, 1990.

431. ZDEBEL, Dirk. Bach und ich: Leben und Werk des brasilianischen Komponisten Heitor Villa-Lobos. Gitarre und Laute, Kassel, v. 8, n 4, p. 24-29, 1986; v. 8, no. 6, p. 28-35, 1986; v. 9, n² 2, p. 51-55, 1987.

432. ZVENGROWSKI, Steven Theodore. Structural patterns found in Prelude number 4 by Heitor Villa-Lobos. The Soundboard, Cypress, v. 6, $n^{\circ} 3, p$. 86-89, 1979.

\section{III - OBRAS DE REFERÊNCIA COM INFORMAÇÕES SOBRE O VIOLÃO E INSTRUMENTOS SIMLARES NO BRASIL}

433. ANDRADE, Mário de. Dicionário musical brasileiro; coordenação Oneyda Alvarenga, 1982-84, Flávia Camargo Toni, 1984-89. Belo Horizonte, Itatiaia; [Brasília], Ministério da Cultura; São Paulo, Instituto de Estudos Brasileiros da Universidade de São Paulo e Editora da Universidade de Sãao Paulo, 1989. xxxiii, 701 p. (Coleção Reconquista do Brasil, 2a. série, v. 162) 
434. AZEVEDO, Luis Heitor Correia de; MATOS, Cleofe Person de; REIS, Mercedes de Moura. Bibliografia musical brasileira (1820-1950). Rio de Janeiro, Ministério da Educação e Saúde / Instituto Nacional do Livro, 1952. 252 p. (Coleção B-I, Bibliografia, v. 9)

435. BARBALHO, Grácio. O popular em 78 rotações. Rio de Janeiro, Ed. do Autor, 1969. 192 p.

436. Bibliografia do folclore brasileiro; organizada por Braulio do Nascimento; colaboração de Cydnéa Bouyer. Rio de Janeiro, Biblioteca Nacional, 1971.353 p. (Coleção Rodolfo Garcia - série B-Catálogos e Bibliografias)

437. Bibliografia da música brasileira 1977-1984. São Paulo, Escola de Comunicações e Artes da USP e Centro Cultural de São Paulo, 1988. viii, $275 \mathrm{p}$.

438. Bibliografia de música brasileira. São Paulo, s.c.p. [ECA-USP], 1978. 287 $p$.

439. CARDOSO, Sylvio Tullio. Dicionário biográfico de música popular. Rio de Janeiro, Empresa Gráfica Ouvidor, 1965. 351 p.

440. CASCUDO, Luís da Câmara. Dicionário do folclore brasileiro. 2a., revista e aumentada. Rio de Janeiro, Instituto Nacional do Livro, 1962.2 v. (Enciclopédia Brasileira, Biblioteca de Obras Subsidiárias, série A, v. $\left.6, \mathrm{n}^{\circ} 1\right)$.

441. CASTRO-MENDIVIL, L. Felipe. $A$ guide to the recorded music for the classical guitar. Modesto, publ. by the author, $1983.77 \mathrm{p}$.

442. CASCUDO, Luis da Câmara. Instrumentos negros do nordeste brasileiro. Movimento brasileiro, Rio de Janeiro, v. 1, no.3, mar. 1929. 86.

443. Catálogo de autores brasileiros. Rio de Janeiro, Casa Artur Napoleão, 1960.

444. Catálogo geral da Casa A. Napoleão, de Sampaio, Araujo \& Cia. [Rio de Janeiro], Tipografia Lenzinger, 1915. 209 p.

445. Catálogo geral dos discos Odeon e Columbia; até dezembro de 1945. Rio de Janeiro, s. ed., 1945.

446. Catálogo geral de música popular brasileira. Rio de Janeiro, Edições Vitle, $1970.125 \mathrm{p}$.

447. Catálogo das músicas sob controle da SDDA; repertório do Brasil, do mundo, de todos os gêneros e todas as épocas. Rio de Janeiro, s.ed., 1972. v. 1.

448. Catálogo geral de músicas, métodos e álbuns para: violão, 2 violões, bandolin, banjo, cavaquinho e violão-tenor. São Paulo, s.ed., s.d.

449. Catálogo de obras de Isaías Sávio. Violão e Mestres, São Paulo, v. 2, no.7, p. 14-20, 1967.

450. Catálogo de obras nacionais da Ed. A. Napoleão. Rio de Janeiro, Ed. Fermata do Brasil, 1968. 35 p. 
451. Catálogo departituras de autores brasileiros; organizado por A. Migliavacca, Luís A. Milanesi e Maria C. de Sousa. São Paulo, ECA-USP, 1977. 118 p.

452. CLARK, David L. Music for guitar and lute; bibliography. Exeter, Exeter City Library, 1972. 36 p.

453. COLONELLI, Cristina Argenton. Bibliografia do folclore brasileiro. São Paulo, Conselho Estadual de Artes e Ciências Humanas, 1979. 294 p. (Coleção Folclore, $\left.n^{\circ} 19\right)$

454. Dicionário de música Zahar. Rio de Janeiro, Zahar Editores, 1985. 424 p.

455. Discografia brasileira em $78 \mathrm{rpm}$. Rio de Janeiro, Funarte, $1982.5 \mathrm{v}$.

456. Discografia de música erudita brasileira. São Paulo, s.c.p. [ECA-USP], 1978. $279 \mathrm{p}$.

457. Enciclopédia da música brasileira; erudita, folclórica, popular. São Paulo, Art Ed., 1977. 2 v.

458. FANCINI, Pietro. Discografia della musica per chitarra di Heitor VillaLobos. Il Fronimo, Milano, v. 15, nº 61, p. 31-35, 1987.

459. GILMORE, George \& PEREIRA, Mark. Guitar music index: a crossindexed and graded listing of music in print fơr classical guitar band lute. Honolulu, Galliard Press, 1976.

460. GREENE, T. F. Music for guitar and strings. American string teacher. v. $23, \mathrm{n}^{\circ} 2$, p. 26-27, 1973.

461. Guia prático e temático n. 2 das edições do grupo editorial "Ricordi" indicadas para o curso completo de violão; classificadas por grau de dificuldade. [São Paùlo], Grupo Editorial Ricordi, 1981. 206 p.

462. HECK, Thomas F. Guitar music in the archive of the Guitar Foundation of America. Sullivant Hall, Guitar Foundation of America, 1981. 87 p.

463. HÖFT, Brigitte. Gitarre und Laute: ihre Musik in Vergangenheit und Gegenwart; ein Noten-, Schriften- und Schallplattenverzeichnis. Mannheim, Stadtbücherei Mannheim, Musikabteilung, 1973. 51 p.

464. IAFELICE, Carlos. Gênios da música; biografia de compositores célebres; origem e dados completos sobre instrumentos musicais. São Paulo, Livraria Trio Editora Ltda., 1974. 197 p.

465. KLEIN, Rudolf. Bücher über die Gitarre und Gitarrenmusik. Die Zupfmusik, v. 14, $\mathrm{n}^{\mathrm{0}}$ 4, p. 51-52. 1961.

466. LIBBERT, Jürgen. Fachliteratur für Gitarristen. Gitarre und Laute, Kessel, v. 1, no 1, p. 44-47, 1979.

467. LIBBERT, Jürgen. Gitarre und andere Zupfinstrumente: eine Glosse zu Schotts neuem Katalog aus der Sicht eines Verbrauchers. Gitarre und Laute, Kassel, v. 2, n 1, p. 30-33, 1980.

468. LIMA, Rossini Tavares de. A Ciência do folclore (segundo diretrizes da 
Escola de Folclore). São Paulo, Ricordi, 1978. 101 p.

469. LIRA, Mariza. Brasil sonoro; gêneros e compositores populares. Rio de Janeiro, A Noite, s.d. 313 p.

470. MACHADO, Raphael Coelho. Dicionario musical [...]; $3^{\mathrm{a}}$ ed. augm. pelo autor e por Raphael Machado Filho. Rio de janeiro, Garnier Livreiro Editor, s.d. [c. 1865], 280 p.

471. MAIER, Peter. Schalplattenverzeichnis: Gitarre, Laute, Zupfinstrumente. Hamburg, Verlag Gitarre aktuell, 1983. 222 p.

472. MARIZ, Vasco. Dicionário biográfico musical. 2a., revista e aumentada. Rio de Janeiro, Philobiblion; [Brasilia], Instituto Nacional do Livro, 1985. $286 \mathrm{p}$.

473. MASLEN, J. Guitars and guitar playing; a list of selected references and music. Melbourne, State Library of Victoria, 1966. 43 p. (Victoria, State Library, Research Service Bibliographies, v. 4)

474. McCREADIE, Sue (ed.). Classical Guitar Companion. Dorset, Musical New Services Ltda., 1982. 101 p. (A Guitar Magazine project)

475. McCUTCHETON, Meredith. Guitar and vihuela; an annotated bibliography. New York, Pendragon Press, 1985. 353 p. (RILM Retrospectives, v. 3)

476. MOSER, Wolf. Gitarre-Musil: ein internationaler Katalog. Hamburg, Der Volksmusikverlag, 1973-1977. 2 v.

477. OBRECHT, Jan. Guitar books. Guitar player, Saratoga, v. 13, $\mathrm{n}^{\circ} 10, \mathrm{p}$. 79-98, 1979.

478. PRAT, Domingo. Diccionario de Guitarristas; Diccionario biografico, bibliografico, historico, critico de guitarras (instrumentos afines), guitarristas (profesores, compositores, concertistas, lahudistas, amateurs), guitarreros (luthiers), danzas y cantos, terminologia. Buenos Aires, Casa Romero y Fernandez, [1934]. 468 p.

479. PURCELL, Ronald C. Classical guitar, lute and vihuela discography. Melville, Belwin-Mills, 1976. vii, 116 p.

480. REZITS, Joseph. Guitar-music in print. San Diego, Kjos, 1981. 500 p.

481. RICHARD, Charles E. Handbook of classical guitar music: a selected, annotated catalogue. San Francisco, Lone Mountain College, 1973. M.A. thesis.

482. SANTOS, Egberto Eloy. To the bibliography of the guitar. Guitar news. $\mathrm{n}^{\circ} 116$, p. 14-15, apr./jun. 1971.

483. SCHWAB, Alceu. Bibliografia da música popular brasileira. Curitiba, Ed. do Autor, 1984. 80 p.

484. SCHWARZ, Werner. Guitar bibliography; An international listing of theoretical literature on classical guitar from the beginning to the present / Gitarre-Bibliographie; Internationales Verzeichnis der theoretischen 
Literatur zur klassischen Gitarre von den Anfängen bis zur Gegenwart; by / von Werner Schwarz; with the assistance / unter Mitarbeit von Monika Haringer; Foreord by/Vorwort von SiegfriedBehrend. München, New York, London, Paris, K.G. Saur, 1984. xxii, 257 p.

485. SINZIG, Pedro. Pelo mundo do som; dicionário musical. 2a. Rio de Janeiro, São Paulo, Porto Alegre, Livraria Kosmos Ed. e Erich Eichner \& Cia Ltda., 1959. $612 \mathrm{p}$.

486. VASCONCELOS, Ary. Carinhoso, etc.: história e inventário do choro. Rio de Janeiro, Ed. do Autor, 1984. 271 p.

487. VASCONCELOS, Ary.. Panorama da música popular brasileira. São Paulo, Martins, 1964. 2 v.

488. VASCONCELOS, Ary. Panorama da música popular brasileira na "Belle Époque". Rio de Janeiro, Livraria Sant'Anna, 1977. 454 p.

489. VASCONCELOS, Ary. Raizes da música popular brasileira. Rio de Janeiro, Rio Fundo Ed., 1991. 324 p.

490. Villa Lobos, sua obra. $3^{\text {a }}$, Rio de Janeiro, Museu Villa-Lobos, 1989. 324 p.

Paulo Augusto Castagna é pesquisador da música brasileira, Mestre em Música pela Escola de Comunicações e Artes da Universidade de São Paulo e professor da Faculdade Santa Marcelina e da Faculdade de Música Carlos Gomes, São Paulo.

Werner Schwarz é bibliotecário diplomado pela Bayerischen Beamtenfachhochschule für Bibliothekswesen de Munique e trabalha como bibliotecário da Bayerischen Staatsbibliothek de Munique e da Universitätsbibliothek de Augsburg. É o autor da Guitar bibliography, de 1984. 